\title{
Mapping of the GEVA Items to the ICF: Preliminary Results Based on the Content of a Tool Guide Used to Assess the Needs of Persons With Disabilities in France
}

\author{
Marie Cuenot ${ }^{*}$ \\ École des Hautes Etudes en Santé Publique, School of Public Health, Rennes, France
}

The aim of this research is two-fold. Firstly, mapping the GEVA items on to the ICF will allow identifying those items that are covered by the ICF and assist in improving the data collection process. Secondly this work will provide a first exploration of the items that are not covered by the ICF and that could lead to potential proposals for updating the ICF. The preliminary results show that the items of the GEVA 2008 general version are partly covered by the ICF 2017 Browser version categories. In every section of the GEVA, some

OPEN ACCESS

Edited by:

Michaela Coenen,

Pettenkofer School of Public

Health, Germany

Reviewed by:

Patricia Welch Saleeby,

Bradley University, United States

Olaf Kraus De Camargo,

McMaster University, Canada

${ }^{*}$ Correspondence:

Marie Cueno

marie.cuenot@ehesp.fr

Specialty section

This article was submitted to

Human Functioning,

a section of the journal

Frontiers in Rehabilitation Sciences

Received: 07 June 2021

Accepted: 13 August 2021

Published: 14 September 2021

Citation:

Cuenot M (2021) Mapping of the GEVA Items to the ICF: Preliminary

Results Based on the Content of a Tool Guide Used to Assess the Needs of Persons With Disabilities in France.

Front. Rehabilit. Sci. 2:721685

doi: 10.3389/fresc.2021.721685 of the items might be coded with ICF codes coming from the following ICF components: Body functions, Activities and Participation, Environmental factors, Personal factors. The items of the section 6 remains those mostly covered by the ICF. Throughout the GEVA, many environmental factors are documented. Although further analysis is needed to better inform the use of qualifiers (performance, capacity, satisfaction) together with the activities and the environmental factors, the identified ICF codes could assist in improving the data collection process. Finally, some items might be discussed to become potential ICF updates proposals.

Keywords: ICF, assessment, mapping, France, GEVA disability assessment tool

\section{INTRODUCTION}

How should the needs of persons with disabilities be assessed so as to enable to live with optimum independence, and the means to live and participate in accordance to their wishes? In the last 50 years, France has developed a succession of laws progressively building a legal framework that aims to ensure the rights to individualized compensation measures and the rights for general accessibility to all.

The main concepts, principles, values, and rights are well-known and accepted. However, their implementation may be considered as an on-going search for improvements.

France has been involved in several international processes such as (1) the work related to the concept of disability. This includes the collaboration with WHO during the revision of the International Classification of Impairments, Disabilities, and Handicaps (1980), and the on-going maintenance of the International Classification of Functioning, Disability, and Health (ICF, WHO, 2001) and (2) the work related to the UN Convention on the rights of persons with disabilities (2006) development process. In 2010, France, together with the European Union, ratified the UN Convention. 
France may broadly be described as a welfare state, and accordingly the provision for persons with disabilities needs is based on the recognition of an administrative status, namely "persons with disabilities." The administrative system is complex and depends on the origin of the impairments or disabilities (work, health, army, life accident, etc.), and different allowances may be granted.

The 2005-102 Law "For equal rights and opportunities, participation and citizenship of persons with disabilities" has provided a new framework focusing on the right for compensation and accessibility. Firstly, this law gives a definition of disability as: "any limitation to activity or restriction to participation to life in society, that one may undergo in one's environment, due to substantial, long-term or permanent alteration of one or more physical, sensory, mental or cognitive functions, severe multiple and profound disabilities or a disabling health condition." Although this definition does contain the concepts found in the ICF, as underlined by the UN Special Rapporteur on the rights of persons with disabilities (1): “[... the definition of disability [...] focuses on the impairment, instead of a person's interaction with the environment and existing barriers, and should therefore be revised." Hence, the implementation of the concepts might be improved.

Nevertheless, this law has led to the set-up of, in each of the 102 French administrative territorial entities, a one-stop counter [Maison Départementale des Personnes Handicapées $(\mathrm{MDPH})]$ that manages the granting of several different disability benefits, one of which being the Prestation de compensation $\mathrm{du}$ handicap "PCH" for citizens aged under 60 years. The MDPHs are in charge of assessing the situations and needs for the compensatory support of persons with disabilities. Each is composed of two bodies: (1) a multidisciplinary team (medical doctors, occupational therapists, psychologists, social workers, etc.) in charge of the assessment of the needs; (2) an executive board, the "Commission for the rights and independence of persons with disabilities," composed of professionals as well as the representatives of organizations of persons with disabilities. These commissions make all decisions related to the provision of financial, technical, and human aid based on the multidisciplinary assessment, related to the development of a personalized compensation plan. The network of local authorities is supported by a national central authority (national fund of solidarity for autonomy-Caisse Nationale de Solidarité pour l'Autonomie (2) in charge of the implementation of a disability policy throughout the country.

In 2008, a national decree (2008-110, February 6, 2008) provided a guide "Guide d'évaluation multidimensionnelle" (GEVA), for the multidimensional assessment of the needs of persons with disabilities. The aim is to ensure, to the greatest extent possible, equality in the treatment of requests of individuals, equity in granting benefits, and a harmonized countrywide assessment of the situation of persons with disabilities in drawing up individualized support plans. It allows the gathering of information about the situation of an individual, summarizes the main key points of the assessment, and supports the decision process. Section 6 of GEVA aiming at supporting the decision taken to allocate the PCH has been explicitly built based on ICF categories and qualifiers.
The general version of this guide, 40 pages, has been developed in 2008 (2) and was first designed to assess the needs of adults aged under 60 years. Several complementary versions do exist, especially some focusing on education and children. As mentioned in a 2014 national study, "Generally speaking, the GEVA is used as a reference framework, but many MDPH have adapted it making their own and simplified versions. Professionals involved in assessment use the sections that seem most relevant and useful to them in relation to the situation. [...] A majority of the MDPH use a tool for gathering information at the individual's home. Half of these tools are ad-hoc tools that contain GEVA items" [(3), p. 36, Translation M. Cuenot].

This initial version provided to the professionals contains no codes and no formal procedure designed to be used for data collection. Only in the annex of the 2008 decree, some hierarchical ad hoc codes are provided for each item and each possible response. The hierarchy is organized by the order of GEVA sections.

The aim of this research is two-fold. Firstly, mapping of the GEVA items onto the ICF will allow to identify those items that are covered by the ICF and assist in improving the data collection process. Secondly, this work will provide the first exploration of the items that are not covered by the ICF, and then could lead to potential additional proposals for updating the ICF. After introducing the method used for this mapping, some preliminary results will be described and then discussed.

\section{METHODS}

The items of the general 2008 paper-based version of the GEVA have been used as a reference version for this mapping (2). They have been translated into English by the author of this paper. Table 1 gives an overview of the content divided up into eight sections. Our analysis did not only take into account the GEVA Section 6 explicitly related to Activities, but also the GEVA Sections $1-5$, the Sections 7 and 8 being merely the summaries of the other sections. We hypothesized that some other sections could also be coded with the ICF.

The linking rules formulated by Cieza et al. $(4,5)$ have guided the mapping work. The ICF 2017 browser version, currently available online, has been used as the reference ICF version for this work. In a general statistic approach, every different GEVA item has been counted in Sections 1-6, thus not including duplicated ones and counting only one ICF category for one GEVA item. The main results presented here are based on a qualitative analysis of the content of the GEVA for the aim is rather showing which ICF categories may be used to code the GEVA items than showing how many GEVA items are coded (several GEVA items may correspond to one same ICF category or are duplicated several times throughout the GEVA).

\section{RESULTS}

Preliminary results show that the GEVA items are partly covered by the ICF. The general statistic approach allows to estimate that $80 \%$ (343 of 435 ) of the GEVA items can be covered by the ICF 
TABLE 1 | Overview of the GEVA 2008 sections and corresponding covered ICF components.

\begin{tabular}{|c|c|c|}
\hline Sections & Overview of content & ICF components \\
\hline Identification: & $\begin{array}{l}\text { Title; Name; ID; Initial reasons of assessment; } \\
\text { Life project and wishes of the person; } \\
\text { Acquaintances' or legal representative's opinion }\end{array}$ & $\mathrm{PF}$ \\
\hline $\begin{array}{l}\text { Section 1: } \\
\text { Family, } \\
\text { social, } \\
\text { and financial situation }\end{array}$ & $\begin{array}{l}\text { Family status; List of persons currently in the household } \\
\text { Social situation in relation to education or employment, including child care arrangements for } \\
\text { young children } \\
\text { Individual financial resources } \\
\text { Elective offices; related needs for human assistance. }\end{array}$ & PF; D; E \\
\hline $\begin{array}{l}\text { Section 2: } \\
\text { Housing } \\
\text { and living conditions }\end{array}$ & $\begin{array}{l}\text { Housing: accommodation, housing types and characteristics (accessibility; comfort) } \\
\text { Services and building accessibility } \\
\text { Transportation: school; human assistance and adaptations }\end{array}$ & PF; D; E \\
\hline $\begin{array}{l}\text { Section 3: } \\
\text { Training and professional path }\end{array}$ & $\begin{array}{l}\text { Education path: background and orientation; learning assesment and adaptations; } \\
\text { professionals' opinion } \\
\text { Professional path: plan; situation; status; workstation and working conditions arrangements; } \\
\text { job coach or psychologist's opinion; arrangements for maintaining a job; skills assessment. }\end{array}$ & PF; D; E \\
\hline $\begin{array}{l}\text { Section 4: } \\
\text { Medical information }\end{array}$ & $\begin{array}{l}\text { Pathological origin of the disabilities; medical background; clinical information (vision; hearing); } \\
\text { symptoms; foreseeable evolution } \\
\text { Impairments (see regulatory framework); healthcare provision } \\
\text { Constraints: personal assistive devices; food; natural environment }\end{array}$ & $\begin{array}{l}(\mathrm{ICD}-10) \\
\mathrm{B} ; \mathrm{PF} ; \mathrm{D} ; \mathrm{E}\end{array}$ \\
\hline $\begin{array}{l}\text { Section 5: } \\
\text { Psychological assessment }\end{array}$ & (Neuro-)Psychological and/or memory assessment & PF \\
\hline $\begin{array}{l}\text { Section 6: } \\
\text { Activities }\end{array}$ & $\begin{array}{l}\text { 1. General tasks and demands, and interpersonal relationships } \\
\text { 2. Mobility } \\
\text { 3. Self-care } \\
\text { 4. Communication } \\
\text { 5. Domestic and daily life } \\
\text { 6. Applying knowledge and learning } \\
\text { 7. Tasks and demands related to education } \\
\text { 8. Tasks and demands related to employment }\end{array}$ & B; D; E \\
\hline $\begin{array}{l}\text { Section 7: } \\
\text { Assistance and care provided }\end{array}$ & $\begin{array}{l}\text { Human assistance (acquaintances, professionnals, joint collaboration) } \\
\text { Organization of a usual day and week } \\
\text { Professionals related to the education project } \\
\text { Summary-Key points to be emphasized } \\
\text { Discussion with the concerned person about the assessment } \\
\text { Eligibility criteria (severe and complete difficulties identified) } \\
\text { Identified needs in relation to different activities }\end{array}$ & PF; B; D; E \\
\hline $\begin{array}{l}\text { Section 8: } \\
\text { Assessment summary }\end{array}$ & Summary of assessment, intended to the Commission's attention & PF; B; D; E \\
\hline
\end{tabular}

categories. In each of the six considered sections of the GEVA, some of the items may be coded with the ICF codes. Hence, not only the items of the Section 6 of the GEVA explicitly relate to Activities but also some items of the other GEVA Sections $1-5$ belong to the universe of the ICF. The covered items are related to the following ICF components: Body functions (B), Activities and Participation (D), Environmental factors (E), and Personal factors (PF).

Some items are covered by other international classifications. In Section 4, the information related to diseases and rare diseases and to hearing and vision could be coded with ICD-10 codes. Some items may also be covered by the 1980 ICIDH categories. Indeed, some parts of the national regulatory framework still use impairments and disabilities to specifically fix the disability rates (Guide-barème). These impairment-related items may be mapped onto some ICF B categories and a related qualifier (Table 2).

The section in which the GEVA items are mostly covered by the ICF D chapters remains Section 6 (Table 2). Each item of this section is explicitly intended to be assessed through the two qualifiers: functional capacity and performance. Functional capacity should be assessed with the following scale, which is similar to the one recommended for the ICF: "0": No difficulty; "1": Mild difficulty; " 2 ": Moderate difficulty; "3": Severe difficulty; "4": Total difficulty; and "9": Non-applicable. Performance should be assessed with another scale: a-activity performed alone; b-activity partially performed with human assistance; c-activity performed with continued assistance; and d-activity not performed.

This performance scale provides the information about the environment, especially mentioning the potential impact of human assistance on the performed activity. This means that conceptually the data that might be collected at that stage should contain one related to $\mathrm{D}$ and one related to $\mathrm{E}$. The following general five types of $\mathrm{E}$ are required to be documented as facilitators or barriers during the performance assessment: human environment [ICF chapter e3 Support and relationships]; technical assistance [e1 Products and technology] housing 
TABLE 2 | GEVA items covered by ICF categories (exact matches).

\section{GEVA item}

\section{Section 4}

Intellectual and cognitive impairments

Mental impairments

Hearing impairments

Language impairments

Vision impairments

Visceral impairments

Motor impairments

\section{Section 6}

1.1 Orientation to time

1.2 Orientation to space

1.4 Memorize

4.2.1 Hearing sounds

4.2.5 Localization of sound source

4.3 Seeing

8.8.1 Seeing colors

8.8.2 Depth perception

3.6.1 Using one's respiratory functions

2.15 Two-hand coordination

\section{Section 2}

\section{Section 6}

1.3 Focusing attention

1.5 Making decisions

1.6 Taking initiatives

1.6.2 Spontaneously forming relationships

1.6.3 Spontaneously undertaking a simple activity

1.6.4 Spontaneously undertaking a complex activity

1.7 Managing one's own safety

1.7.1 Not endangering other's life or one's own life

1.7.2 Adapted reaction in a hazardous situation

1.8 Respecting social rules

1.9 Relating to others according to social rules

1.10 Control one's behavior in interactions with others

1.11 Relating with peers

1.12 Having intimate relationships

2.1 Standing

2.1.1 Lying down

2.1.2 Sitting

2.2 Transferring oneself

2.3 Shifting the point of support

2.4 Maintaining a sitting position

2.5 Maintaining a standing position

2.6 Walking

2.7.1 Moving around within the home

2.7.2 Moving around outside the home

2.8 Climbing stairs

2.9 Using public transportation

2.10 Using one's own vehicle

2.11 Driving a vehicle

2.14 Fine hand use

2.16 Lifting and carrying objects (including while moving around)
ICF 2nd or 3rd-level codes

\section{B}

b1 Mental functions + qualifiers

b1 Mental functions + qualifiers

b230 Hearing functions + qualifiers

b3 Voice and speech functions + qualifiers

b210 Seeing functions + qualifiers

Functions related to the digestive system (b510-b539) + qualifiers

b7 Neuromusculoskeletal and movement-related functions + qualifiers

\section{B}

b1140 Orientation to time

b1144 Orientation to space

b144 Memory functions

b2300 Sound detection

b2302 Localization of sound source

b210 Seeing functions

b21021 Color vision

b21000 Binocular acuity of distant vision

b440 Respiration functions

b7602 Coordination of voluntary movements

d850 Remunerative employment

\section{D}

d160 Focusing attention

d177 Making decisions

d177 Making decisions

d7200 Forming relationships

d2100 Undertaking a simple task

d2101 Undertaking a complex task

d570 Looking after one's health

d240 Handling stress and other psychological demands

d7203 Interacting according to social rules

d7202 Regulating behaviors within interactions

d7402 Relating with equals

d770 Intimate relationships

d4104 Standing

d4100 Lying down

d4103 Sitting

d420 Transferring oneself

d4106 Shifting the body's center of gravity

d4153 Maintaining a sitting position

d4154 Maintaining a standing position

d450 Walking

d4600 Moving around within the home

d4602 Moving around outside the home and other buildings

d4551 Climbing

d4702 Using public motorized transportation

d4701 Using private motorized transportation

d475 Driving

d440 Fine hand use

d430 Lifting and carrying objects 
TABLE 2 | Continued

\section{GEVA item}

3.1 Washing oneself

3.2 Caring for body

3.3 Toileting and using the toilets

3.4 Putting on and taking off clothes

3.5 Eating, drinking

3.6 Looking after one's health

3.6.2 Caring for oneself

3.6.4 Monitoring one's own diet

4.1 Speaking

4.2.2 /0.3 /0.4 Understanding others' speaking face to face/in a

group/in a noisy environment

4.4 Using communication devices and techniques

4.4.1 Using a phone

4.4.2 Using other communication devices and techniques

4.5 Understanding a simple sentence

4.6 Maintaining a conversation

4.7 Producing and receiving non-verbal messages

5.1 Shopping

5.2 Preparing a simple meal

5.3 Doing housework

5.4 Taking care of clothes and garments

5.5 Taking care of one's own family

5.6 / 5.6.1 Managing one's own money daily and administrative tasks

5.6.2 Managing one's bank account

5.8 Having informal relationships with neighbors

5.9 Participating in community, social and civic life

5.9.3 Participating in local life

6.1 Reading

6.2 Writing

6.3 Calculating

6.4 Acquiring know-how skills; 6.5 Applying know-how skills

7.1 Learning to read

7.2 Learning to write

7.3 Learning to calculate

7.6 / 8.1/ 7.6.9 Respecting basic rules in relation to

education/employment; Respecting school rules

7.6.8 / 8.6 Working with a team, in relation to education/employment

8.1.3 Respecting hierarchical relations

8.1.4 Participating in meetings

8.7 / 8.7.1 Physical tasks/Lifting and moving heavy objects

8.7.2 Trunk twisting while working

8.7.3 Working in various positions

8.7.4 Working in a squatting position

8.7.9 Using one's feet to use a machine

\section{ICF 2nd or 3rd-level codes}

\author{
d510 Washing oneself \\ d520 Caring for body parts \\ d530 Toileting \\ d5400 Putting on clothes; d5401 Taking off clothes \\ d550 Eating; d560 Drinking \\ d570 Looking after one's health \\ d5702 Maintaining one's health \\ d5701 Managing diet and fitness \\ d330 Speaking \\ d310 Communicating with-receiving - spoken messages
}

d360 Using communication devices and techniques

d3600 Using telecommunication devices

d3609 Using communication devices and techniques, unspecified

d3100 Communicating with - receiving - simple spoken messages

d350 Conversation

d315 Communicating with - receiving - nonverbal messages; d335 Producing

non-verbal messages

d6200 Shopping

d6300 Preparing simple meals

d640 Doing housework

d6400 Washing and drying clothes and garments

d660 Assisting others

d860 Basic economic transactions (managing one's budget, administrative tasks)

d865 Complex economic transactions (managing one's bank account)

d7501 Informal relationships with neighbors

d9 Community, social and civic life

d950 Political life and citizenship

d166 Reading

d170 Writing

d172 Calculating

d155 Acquiring skills

d140 Learning to read

d145 Learning to write

d150 Learning to calculate

d7203 Interacting according to social rules

d7402 Relating with equals

d8451 Maintaining a job

d3551 Discussion with many people

d430 Lifting and carrying objects

d4305 Putting down objects

d4309 Lifting and carrying, unspecified

d4151 Maintaining a squatting position

d4350 Pushing with lower extremities adaptations [e1158 Products and technology for personal use in daily living, other specified]; services [e5 Services, systems, and policies]; and animal assistance [e350 Domesticated animals]. Additionally, in this GEVA Section 6, a list of items are given for a more in-depth assessment of the human, technical, and animal assistance provided in each life domain. A related satisfaction assessment scale is eventually included to collect the point of view of the individual about the situation: complete satisfaction; satisfaction; mild satisfaction; and no satisfaction.

Hence, throughout the GEVA sections, many $\mathrm{E}$ are listed that may be documented. Table 3 presents the corresponding ICF E categories that are covered. Some require additional information 
TABLE 3 | ICF Environmental factors documented throughout the GEVA and related GEVA sections.

E1 Products and technology
e1101 Drugs
e1108 Products or substances for personal consumption, other
specified

e1151 Assistive products and technology for personal use in daily living

e1158 Products and technology for personal use in daily living, other specified

e120 Products and technology for personal indoor and outdoor mobility and transportation

e1201 Assistive products and technology for personal indoor and outdoor mobility and transportation

e1251 Assistive products and technology for communication e130 Products and technology for education

e1301 Assistive products and technology for education

e135 Products and technology for employment

e150 Design, construction and building products and technology of buildings for public use;

e1500 Design, construction and building products and technology for entering and exiting buildings for public use

e1501 Design, construction and building products and technology for gaining access to facilities inside buildings for public use e1508 Design, construction and building products and technology of buildings for public use, other specified

e1550 Design, construction and building products and technology for entering and exiting of buildings for private use

e1551 Design, construction and building products and technology for gaining access to facilities in buildings for private use e1650 Assets

e198 Products and technology, other specified

e225 Climate

e2250 Temperature

e2251 Humidity

e240 Light

e2450 Day/night cycles

e2458 Time-related changes, other specified

e250 Sound

e2500 Sound intensity

e255 Vibration

e260 Air quality

e2601 Outdoor air quality

e298 Natural environment and human-made changes to environment, other specified

e3 Support and Relationships

e310 Immediate family

e325 Acquaintances, peers, colleagues, neighbors and community members

e340 Personal care providers and personal assistants

e350 Domesticated animals

e355 Health professionals

e398 Support and relationships, other specified

e399 Support and relationships, unspecified
6: General Environmental factor technical environment

4: Regular treatments

4: Food constraints

4: Urinary ostomy and catheter, digestive ostomy, gastrostomy, jejunostomy, tracheotomy, ventilation unit

4: Dependence on another machine

6: General Environmental factor housing

2: Adapted vehicule

4: Walking sticks, wheelchair

4: Hearing aid

3: Adaptations during school assessments

6: Adapted teaching material, computers

3: Workstation accommodation

2: Accessibility of postal, and education facilities and services

2: Accessibility of the housing

2: Lift in the housing

2: Other elements of accessibility of the housing

2: Accessibility of shops, banks

2: Accessibility of living room, kitchen, bedroom, toilets, bathroom, vertical and horizontal inside circulation

2: Owner of housing

4: Equipment

4: Weather

4: Cold, heat

4: Humidity

4: Light

6: Night work

6: Working assuming schedules modifications

4: Noise

6: Working in a noisy environment

6: Working in an environment with vibrations

6: Working in specific respiratory environments

4: Dust, chemical agents

4: Other external factor constraints

6: General Environmental factor human environment

6: Spouse, child, parent, brother/sister, other parent

6: Friend, neighbor, mutual support group

3: Human assistance during school assessments

4: Personal care assistant

6: Personal assistant at school

6: General Environmental factor animal environment

4: PT, OT, nurse, speech therapist, psychologist

6: Cued speech interpreters, technicians in writing, sign language interpreters

6: Associated to the general performance qualifier levels $b$ and $c$ 
TABLE 3 | Continued

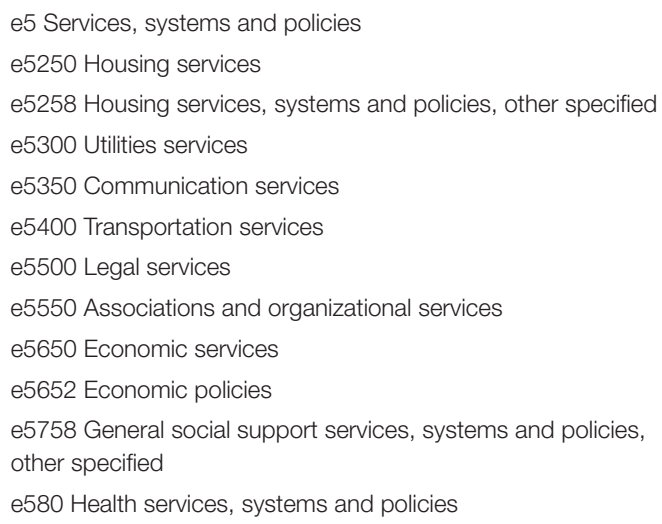

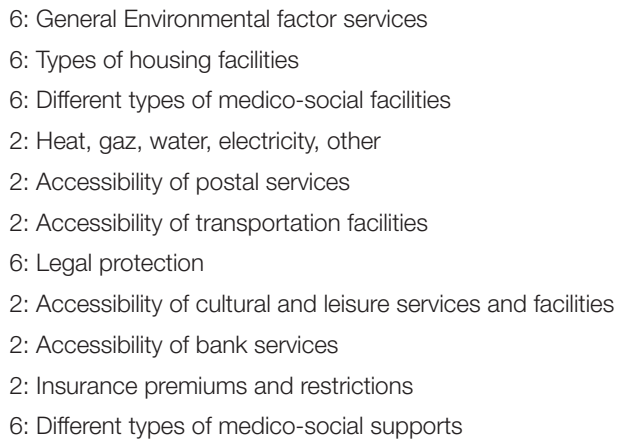

2: Accessibility of other services to know whether they have an impact on the individual situation, as a facilitator or an obstacle. Others only require to be identified as being provided or not. A more in-depth analysis would allow more information on how they are formulated in relation to the ICF E qualifiers. Nevertheless, these preliminary results show that the ICF E Chapters 1, 2, 3, and 5 are documented throughout the GEVA items. The categories of Chapter 4 related to Attitudes are not represented as such.

Throughout the GEVA, some items are also related to PF. Some additional qualitative information is listed in the GEVA and relates to proxy and points of view of professionals about the situation of an individual (psychological, medical, educational, apprenticeship, and professional).

Finally, some GEVA items might be covered by the ICF but no exact match is really possible. Table 4 presents them together with the potentially lacking concept. They are mainly related to D and E. Other GEVA items cannot at all be coded with the ICF for they require qualitative information, either the point of view of other persons in relation to the main one asking for an assessment, or administrative information about some applications in progress and time-related information. The satisfaction qualifier is also not a part of the ICF.

\section{DISCUSSION}

These preliminary results of this GEVA-ICF mapping provides a first overview of the ICF coverage potential. The categories stemming from the D chapters and the Environmental chapters, together with the corresponding qualifiers, are well-represented.
Not completely covered items deal in particular with education and employment (see Table 4). They raise some issues on how to better implement specific adaptations in these two areas and others so as to facilitate the coding and collection of some precise information.

This also underlines the needs to better document the way of interaction of these components together in some specific areas, in particular such as education or employment, which are the two major areas in the individual life project.

In the ICF education category (d820), additional information could then be added in relation to assessment/examination criteria, organizing and checking one's own work, getting organized in the classroom, getting used to school life, using learning (adapted) materials, taking notes, and participating in after-school activities. Several GEVA items also relate to the learning process: learning how to use communication techniques, or basic social rules, asking for help or assistance.

In the employment area, additional information could be added about organizing and checking one's work, working at height, working with the dominant/non-dominant arm, and working in hazardous environments.

Furthermore, the GEVA satisfaction qualifier is currently used and allows a better understanding of the impact of the E. A more in-depth analysis is needed to firstly better inform the use of qualifiers together with $\mathrm{E}$ and secondly to improve the identification of the items directly covered by the ICF definition of PF and others that might not be covered but which provided relevant information for a better understanding of the situation and project of an individual. 
TABLE 4 | GEVA items not completely covered by the ICF.

GEVA item and related GEVA Section
Most precise ICF categories e5850 Education and training services

d950 Political life and citizenship

- Engaging in political life

- Participation in councils where DPO's representatives

are appointed as members by law: Local councils;

national or European parliament; other

Human assistance required in relation to political life;

Other needs

\section{Section 3-4}

School assessment criteria (adaptations, additional time)

Additional time necessary for care provision

Infectious agents

\section{Section 6}

1.6.1 Spontaneously asking for help

3.6.3 Expression of a need for healthcare

5.9.2 Expression of a request for help in relation to one's

own rights

2.12 / 13 Grasping using the dominant

hand/non-dominant hand

3.6.5 Managing one's daily rest

5.9.1 Managing one's free time, participating in cultural

or sport activities

5.10 Going on holiday

7.4 Learning communication techniques

7.5 Learning basic social rules

7.6.3/8.2 Organizing one's work

7.6.4/8.3 Checking one's work

7.7 Getting organized in the classroom

7.6.7 Adaptation to school life

7.8 Using learning materials

7.9 Using materials adapted to one's disabilities

7.10 Taking notes

7.11 Adaptation to examination and assessment conditions

7.12 Participating in after-school activities

8.7.5/8.7.6 Working at height (scale, roof)

8.7.7 Working with the dominant arm above the shoulders' height

8.7.8/non-dominant

8.8.5 Using hazardous tools or machines

8.8.9 Working in environments with risks for the skin e340 Personal care providers and
personal assistants

e5950 Political services

d820 School education

e580 Health services, systems and

policies

e2201 Animals

d570 Looking after one's health

d4401 Grasping

d570 Looking after one's health

d920 Recreation and leisure

d9208 Recreation and leisure, other specified

d3608 Using communication devices and techniques, other specified

d7208 Complex interpersonal interactions, other specified

d820 School education

d8451 Maintaining a job

d820 School education

d820 School education

d820 School education

d820 School education

d820 School education

d4158 Maintaining a body position, other specified

d4308 Lifting and carrying, other specified

d2402 Handling crisis

d2402 Handling crisis d940 Human rights
Potential additional concepts related to ICF chapters

\author{
Child care facilities (e) \\ Local \\ National \\ Transnational \\ Other specified \\ Human assistance related to political \\ engagement (e)
}

Learning assessment criteria

Additional time

Infectious agents (e)

Asking for help or assistance

Dominant hand/Non-dominant hand

Managing one's need for some rest

Managing one's free time

Going on holiday

Learning how to use communication techniques

Learning basic social rules

Organizing one's work

Checking one's work

Getting organized in the classroom

In relation to education

In relation to employment

Getting used to school life

Using learning materials

Using materials adapted to one's

disabilities

Taking notes

Adaptation to examination and assessment conditions

Participating in after-school activities

Working at height

Working with the dominant/non-dominant arm above the shoulders' height

Using hazardous tools or machines

Risks in relation to the skin

In relation to $\mathrm{E}$ and $\mathrm{PF}$, there is also a need to distinguish on one hand the content directly inspired by the French regulatory framework and on the other hand the content based on the ICF concepts and implementation rules. The GEVA has been designed in accordance with the French legal framework and not its whole content may be applied to other social and cultural contexts without adaptation.

The GEVA items not completely covered by the ICF might benefit from the discussions with other ICF experts so as to better evaluate them as potential ICF update proposals. 


\section{CONCLUSION}

This mapping approach shows that firstly the items of the GEVA 2008 general version are partly covered by the ICF 2017 Browser version categories. In every section of the GEVA, some of the items might be coded with the ICF codes obtained from the following ICF components: B, D, E, and PF. The items of Section 6 remains those mostly covered by the ICF. Throughout the GEVA, many E factors are documented. Although further analysis is needed to better inform the use of qualifiers (performance, capacity, and satisfaction) together with the $\mathrm{D}$, and the $\mathrm{E}$, the identified ICF codes could assist in improving the data collection process. Finally, some items might be discussed to become potential ICF update proposals.

\section{REFERENCES}

1. Human Rights Council. Visit to France. Report of the Special Rapporteur on the Rights of Persons With Disabilities. United Nations General Assembly (2019).

2. Caisse nationale de solidarité pour l'autonomie (CNSA). GEVA - Guide d'évaluation multidimensionnelle. (2008). Available online at: https://www.cnsa. $\mathrm{fr} /$ documentation/geva_graphique-080529-2.pdf

3. Ministère des affaires sociales et de la santé, Haut conseil de la santé publique, Cekoïa Conseil. Enquête quantitative sur les modes d'évaluation et de traitement des demandes de compensation du handicap par les MDPH, Rapport final. (2014). Available online at: https:// www.google.com/url? sa $=\mathrm{t} \& \mathrm{rct}=\mathrm{j} \& \mathrm{q}=$ \&esrc $=\mathrm{s} \&$ source $=$ web\&cd=\&ved $=$ 2ahUKEwiloMHi46rwAhXHDGMBHZTfA2wQFjABegQIBhAD\& url=https\%3A\%2F\%2Fwww.hcsp.fr\%2FExplore.cgi\%2FTelecharger \%3FNomFichier\%3Dhcspr20150511_evalbesoinhandicapmdph.pdf\&usg= AOvVaw2WklliwguHt7e3benEF0x9

4. Cieza A, Fayed N, Bickenbach J, Prodinger B. Refinements of the ICF linking rules to strengthen their potential for establishing comparability of health information. Disabil Rehabil. 41:574-83. doi: 10.3109/09638288.2016.1145258

\section{DATA AVAILABILITY STATEMENT}

The raw data supporting the conclusions of this article will be made available by the authors, without undue reservation.

\section{AUTHOR CONTRIBUTIONS}

The author confirms being the sole contributor of this work and has approved it for publication.

\section{ACKNOWLEDGMENTS}

The author would like to thank William Sherlaw for reading the first draft in English.

5. Cieza A, Geyh S, Chatterji S, Kostanjsek N, Üstün B, Stucki G. ICF linking rules: an update based on lessons learned. J Rehabil Med. (2005) 37:2128. doi: 10.1080/16501970510040263

Conflict of Interest: The author declares that the research was conducted in the absence of any commercial or financial relationships that could be construed as a potential conflict of interest.

Publisher's Note: All claims expressed in this article are solely those of the authors and do not necessarily represent those of their affiliated organizations, or those of the publisher, the editors and the reviewers. Any product that may be evaluated in this article, or claim that may be made by its manufacturer, is not guaranteed or endorsed by the publisher.

Copyright (C) 2021 Cuenot. This is an open-access article distributed under the terms of the Creative Commons Attribution License (CC BY). The use, distribution or reproduction in other forums is permitted, provided the original author(s) and the copyright owner(s) are credited and that the original publication in this journal is cited, in accordance with accepted academic practice. No use, distribution or reproduction is permitted which does not comply with these terms. 